\title{
Alternative agents versus prophylactic platelet transfusion for preventing bleeding in patients with haematological disorders after chemotherapy or stem cell transplantation
}

\author{
Lise J Estcourt ${ }^{1}$, Richard Gregg ${ }^{2}$, Simon Stanworth ${ }^{1}$, Carolyn Doree ${ }^{3}$, Marialena Trivella ${ }^{4}$, \\ Michael F Murphy ${ }^{5}$, and Alan Tinmouth ${ }^{6}$ \\ ${ }^{1}$ Haematology/Transfusion Medicine, NHS Blood and Transplant, Oxford, UK \\ ${ }^{2}$ Department of Haematology, University Hospitals Birmingham NHS Foundation Trust, \\ Birmingham, UK \\ ${ }^{3}$ Systematic Review Initiative, NHS Blood and Transplant, Oxford, UK \\ ${ }^{4}$ Centre for Statistics in Medicine, University of Oxford, Oxford, UK \\ ${ }^{5} \mathrm{NHS}$ Blood and Transplant, John Radcliffe Hospital, Oxford, UK \\ ${ }^{6}$ Medicine (hematology) and Pathology Centre for Transfusion Research, The Ottawa Health \\ Research Institute and the University of Ottawa, Ottawa, Canada
}

\begin{abstract}
This is the protocol for a review and there is no abstract. The objectives are as follows:

To determine whether alternative agents (e.g. artificial platelet substitutes, platelet-poor plasma, fibrinogen, rFVIIa, thrombopoietin mimetics) are as effective and safe as the use of platelet transfusions for the prevention of bleeding (prophylactic platelet transfusion) in patients with haematological disorders who are undergoing myelosuppressive chemotherapy or stem cell transplantation. Antifibrinolytics (lysine analogues) will not be included in this review because they have been the focus of another Cochrane review (Wardrop 2013).
\end{abstract}

Copyright () 2014 The Cochrane Collaboration. Published by John Wiley \& Sons, Ltd.

Contact address: Lise J Estcourt, Haematology/Transfusion Medicine, NHS Blood and Transplant, Level 2, John Radcliffe Hospital, Headington, Oxford, OX3 9BQ, UK. lise.estcourt@nhsbt.nhs.uk. lestcourt@ doctors.org.uk.

Editorial group: Cochrane Haematological Malignancies Group.

Publication status and date: New, published in Issue 3, 2014.

CONTRIBUTIONS OF AUTHORS

Lise Estcourt: protocol development, searching, selection of studies, eligibility and quality assessment, data extraction and analysis and content expert.

Richard Gregg: protocol development, searching, selection of studies, eligibility and quality assessment, data extraction and analysis and content expert.

Simon Stanworth: protocol development and content expert.

Carolyn Doree: protocol development, searching and selection of studies.

Marialena Trivella: protocol development and statistical expert.

Sally Hopewell: protocol development and methodological expert.

Mike Murphy: protocol development and content expert.

Alan Tinmouth: protocol development and content expert.

The previous review Estcourt 2012a has now been split into four separate reviews. 


\section{BACKGROUND}

\section{Description of the condition}

Haematological malignancies account for between $8 \%$ and $9 \%$ of all new cancers reported in the UK and US (CDC 2012; ONS 2012), and their incidence is increasing (11\% to $14 \%$ increase in new cases of lymphoma and myeloma between 1991 to 2001, and 2008 to 2010) (Cancer Research UK 2013). The prevalence of these disorders is also increasing due to increased survival rates (Coleman 2004; Rachet 2009). These improved survival rates are due to the introduction of intensive chemotherapy treatments and use of stem cell transplantation (Burnett 2011; Fielding 2007; Patel 2009). Over 50,000 haematopoietic stem cell transplants (HSCT) are carried out annually worldwide (Gratwohl 2010), and are used to treat both malignant and non-malignant haematological disorders. Autologous HSCT is the commonest type of HSCT (57\% to 59\%) (Gratwohl 2010; Passweg 2012). However, chemotherapy and stem cell transplantation can lead to prolonged periods of severe thrombocytopenia (De la Serna 2008; Heddle 2009a; Rysler 2010; Stanworth 2013; Wandt 2012).

Platelet transfusions are used in modern clinical practice to prevent and treat bleeding in thrombocytopenic patients with bone marrow failure secondary to chemotherapy or stem cell transplantation. The ready availability of platelet concentrates has undoubtedly made a major contribution in allowing the development of intensive treatment regimens for haematological disorders (malignant and non-malignant) and other malignancies. The first demonstration of the effectiveness of platelet transfusions was performed in 1910 (Duke 1910). However, it was not until the 1970s and 1980s that the use of platelet transfusions became standard treatment for thrombocytopenic patients with bone marrow failure (Blajchman 2008). Alongside changes in supportive care, the routine use of platelet transfusions in patients with haematological disorders since that time has led to a marked decrease in the number of haemorrhagic deaths associated with thrombocytopenia (Slichter 1980). This has resulted in a considerable increase in the demand for platelet concentrates. Currently, platelet concentrates are the second most frequently used blood component. Administration of platelet transfusions to patients with haematological disorders now constitute a significant proportion (up to 67\%) of all platelets issued (Cameron 2007; Greeno 2007; Pendry 2011), and the majority of these (69\%) are given to prevent bleeding (Estcourt 2012b).

Patients can become refractory to platelet transfusions. In an analysis of the TRAP 1997 study data, there was a progressive decrease in the post-transfusion platelet count increments and time interval between transfusions as the number of preceding transfusions increased (Slichter 2005). This effect was seen irrespective of whether or not patients had developed detectable human leukocyte antigen (HLA) antibodies (Slichter 2005).

Platelet transfusions are also associated with adverse events. Mild to moderate reactions to platelet transfusions include rigors, fever, and urticaria (Heddle 2009b). These reactions are not life-threatening but can be extremely distressing for the patient. Rarer, but more serious sequelae include: anaphylaxis; transfusion-transmitted infections; transfusion-related acute lung injury; and immunomodulatory effects (Benson 2009; Blumberg 2009; Bolton-Maggs 
2012; Heddle 2009b; Knowles 2011; Pearce 2011; Popovsky 1985; Silliman 2003; Taylor 2010).

Any strategy that can safely decrease the need for prophylactic platelet transfusions in haematology patients will have significant logistical and financial implications as well as decreasing patients' exposure to the risks of transfusion.

\section{Description of the intervention}

Platelet transfusions have an obvious beneficial effect in the management of active bleeding in patients with haematological malignancy and severe thrombocytopenia. However, questions still remain on how this limited resource should be used to prevent severe and lifethreatening bleeding (Estcourt 2011). Prophylactic platelet transfusions for patients with chemotherapy-induced thrombocytopenia became standard practice following the publication of several small, randomised controlled trials (RCTs) in the late 1970s and early 1980s (Higby 1974; Murphy 1982; Solomon 1978).

The standard practice in most haematology units across the developed world is to use prophylactic transfusions, in line with guidelines (BCSH 2003; BCSH 2004; Board 2009; NBA 2012; Schiffer 2001; Slichter 2007; Tinmouth 2007). The experimental intervention is to give an alternative treatment, such as artificial platelet substitutes, platelet-poor plasma, recombinant factor VIIa (rFVIIa), fibrinogen or thrombopoietin mimetics.

Anti-fibrinolytics (lysine analogues) will not be included in this review because they are the focus of another Cochrane review (Wardrop 2013).

\section{How the intervention might work}

Most clinical research has focused on the optimal dose for platelet transfusion or the threshold level of platelet counts for prophylactic platelet transfusions, rather than questioning the underlying assumption that prophylactic platelet transfusions are necessary or effective. The most recent randomised controlled trials (RCTs) have established that many patients develop bleeding at some stage during the period of greatest risk, frequently defined as a period of thrombocytopenia (Heddle 2009a; Slichter 2010). This bleeding covers a spectrum of bleeding, from skin changes to, less commonly, intracranial haemorrhage. In Slichter 2010 patients had similar rates of bleeding (17\%) with morning platelet counts within the range of 6 to $80 \times 10^{9} / \mathrm{L}$. This means that a significant number of bleeding episodes are not being effectively treated by prophylactic platelet transfusions. Treatments that target other parts of the clotting cascade may be as effective at treating bleeding as prophylactic platelet transfusions.

Other means of decreasing the incidence of thrombocytopenic bleeding have been suggested. These include the use of artificial substitutes for platelets, treatment with pharmacological agents that act at different parts of the clotting cascade (Mannucci 1997; Wardrop 2013), and growth factor agonists to stimulate the patient's bone marrow to recover more rapidly and therefore decrease the duration of thrombocytopenia (Miao 2012). 


\section{Artificial platelet substitutes}

Artificial platelet substitutes overcome some of the problems associated with prophylactic platelet transfusions derived from donors (limited supply and risk of infection). Various different forms have been suggested and studied including liposomes, nanoparticles, nanosheets and hydrogels (Doshi 2012; Nishiya 2002; Okamura 2009a; Okamura 2009b). These have been shown to be effective in in vitro or animal models (Doshi 2012; Nishiya 2002; Okamura 2009a; Okamura 2009b).

\section{Platelet-poor plasma (PPP)}

Platelet-poor plasma (PPP) is a source of clotting factor concentrates and fibrinogen.

\section{Recombinant factor VIla (rFVIla)}

Recombinant factor VIIa (rFVIIa) is licensed for use in patients with haemophilia and inhibitory allo-antibodies, and for prophylaxis and treatment of patients with congenital factor VII deficiency. It is also used for off-license indications to prevent bleeding in operations where blood loss is likely to be high, and/or to stop bleeding that is proving difficult to control by other means. However, a recent systematic review showed that the effectiveness of rFVIIa outside its licensed indications remains unproven (Simpson 2012).

\section{Fibrinogen}

Fibrinogen is the endogenous substrate for fibrin formation (Manco-Johnson 2009). The formation of a fibrin network, formed by activated platelets and cross-linked fibrin strings, is the endpoint of the coagulation process in-vivo (Sorensen 2011). Multiple in vitro experiments, animal studies, and non-randomised clinical studies have suggested that use of a fibrinogen concentrate may be efficient and safe in controlling perioperative bleeding (Solomon 2009; Sorensen 2011).

\section{Desmopressin}

Desmopressin (DDAVP), a derivative of the anti-diuretic hormone, has been used since the 1970s to treat mild haemophilia A and von Willebrand's disease without the need for blood products (Mannucci 1997). DDAVP increases the plasma levels of factor VIII (FVIII) and von Willebrand factor (vWF) and enhances platelet adhesion to the vessel wall but has no effect on the platelet count (Barnhart 1983; Mannucci 1997; Sakariassen 1984). It has been shown to be effective at preventing bleeding in patients who have normal levels of FVIII and vWF, e.g. patients with uraemia (Mannucci 1997).

\section{Thrombopoietin mimetics}

Thrombopoietin (TPO) is the major regulator of both megakaryopoeisis and thrombopoiesis, it promotes cell differentiation and prevents apoptosis of megakaryocyte colony-forming cells and early megakaryocyte progenitors (Kuter 2010). The two main TPO mimetics in current use are romiplostim (weekly injection) and eltrombopag (daily oral tablet). Romiplostim is recommended by the National Institute for Clinical Excellence (NICE) for use in adults with immune thrombocytopenia (ITP) who have severe disease and a high risk of bleeding (NICE 2011) but eltrombopag is not (NICE 2010). However, in a recent 
systematic review of TPO receptor agonists in chronic ITP there was no evidence to demonstrate that TPO receptor agonists improved significant bleeding events despite significantly increasing platelet response (Zeng 2011).

\section{Assessment of bleeding}

A bleeding assessment has been seen as a more clinically relevant measure of the effect of platelet transfusions than surrogate markers such as platelet increment.

Any review that uses bleeding as a primary outcome measure needs to assess the way that the trials have recorded bleeding. Unfortunately, the way bleeding has been recorded and assessed has varied markedly between trials (Cook 2004; Estcourt 2013a; Heddle 2003).

Retrospective analysis of bleeding leads to a risk of bias because bleeding events may be missed, and only more severe bleeding is likely to have been documented. Prospective bleeding assessment forms provide more information and are less likely to miss bleeding events. However, different assessors may grade the same bleed differently and it is very difficult to blind the assessor to the intervention.

The majority of trials have used the World Health Organization (WHO) system, or a modification of it, for grading bleeding (Estcourt 2013a; Koreth 2004; WHO 1979). One limitation of all the scoring systems that have been based on the WHO system is that the categories are relatively broad and subjective. This means that a small change in a patient's bleeding risk may not be detected. Another limitation is that the modified WHO categories are partially defined by whether a bleeding patient requires a blood transfusion. The threshold for intervention may vary between clinicians and institutions and so the same level of bleeding could be graded differently in different institutions.

The definition of what constitutes clinically significant bleeding has varied between studies. Although the majority of more recent platelet transfusion studies (Heddle 2009a; Slichter 2010; Stanworth 2010; Wandt 2012) now classify it as WHO grade 2 or above there has been greater heterogeneity in the past (Cook 2004; Estcourt 2013a; Koreth 2004). The difficulties with assessing and grading bleeding may limit the ability to compare results between studies and this needs to be kept in mind when reviewing the evidence for the effectiveness of prophylactic platelet transfusions.

\section{Why it is important to do this review}

Although considerable advances have been made in platelet transfusion therapy in the last 40 years, 3 major areas continue to provoke debate.

- Firstly, what is the optimal prophylactic platelet dose to prevent thrombocytopenic bleeding?

- Secondly, which threshold should be used to trigger the transfusion of prophylactic platelets?

- Thirdly, are prophylactic platelet transfusions superior to therapeutic platelet transfusions for the prevention and/or control of life-threatening thrombocytopenic bleeding? 
The initial formulation of this Cochrane review attempted to answer these questions, but there was insufficient evidence available at the time for any definitive conclusions to be drawn (Stanworth 2004). This review was updated (Estcourt 2012a). However, for clarity and simplicity this review has now been split to answer each question separately.

This review will focus on the additional question of whether alternative agents instead of prophylactic platelet transfusions can be used for the prevention and/or control of lifethreatening thrombocytopenic bleeding.

This review will not assess the evidence for antifibrinolytics (lysine analogues) as this is the focus of a recent review (Wardrop 2013). Avoiding the need for unnecessary prophylactic platelet transfusions in haematology patients will have significant logistical and financial implications for national health services as well as decreasing patients' exposure to the risks of transfusion. This knowledge is perhaps even more important in the development of platelet transfusion strategies in the developing world where access to blood components is much more limited (Verma 2009).

The three questions above will be assessed by three further separate reviews.

This review will not assess whether there are any differences in the efficacy of apheresis versus whole-blood derived platelet products, the efficacy of pathogen-reduced platelet components, the efficacy of HLA-matched versus random donor platelets, or differences between $\mathrm{ABO}$ identical and $\mathrm{ABO}$ non-identical platelet transfusions. This is because these topics have been covered by recent systematic reviews (Butler 2013; Heddle 2008; Pavenski 2013; Shehata 2009).

\section{OBJECTIVES}

To determine whether alternative agents (e.g. artificial platelet substitutes, platelet-poor plasma, fibrinogen, rFVIIa, thrombopoietin mimetics) are as effective and safe as the use of platelet transfusions for the prevention of bleeding (prophylactic platelet transfusion) in patients with haematological disorders who are undergoing myelosuppressive chemotherapy or stem cell transplantation. Anti-fibrinolytics (lysine analogues) will not be included in this review because they have been the focus of another Cochrane review (Wardrop 2013).

\section{METHODS}

\section{Criteria for considering studies for this review}

Types of studies-We will include randomised controlled trials (RCTs). There will be no restrictions on language or publication status.

Types of participants-Patients with haematological disorders receiving treatment with myelosuppressive chemotherapy and/or stem cell transplantation. We will include people of all ages, and we will include both inpatients and outpatients.

If trials consist of mixed populations of patients, e.g. those with diagnoses of solid tumours, only data from the haematological subgroups will be used. If subgroup data for 
haematological patients is not provided (after contacting the authors of the trial), the trial will be excluded if fewer than $80 \%$ of participants have a haematological disorder. Any patients that are not being treated with intensive chemotherapy or a stem cell transplant will be excluded. We will include patients with non-malignant haematological disorders (e.g. aplastic anaemia, congenital bone marrow failure syndromes) that are being treated with an allogeneic stem cell transplant.

Types of interventions-We will include the two following comparisons:

1. Alternative agent versus prophylactic platelet transfusion

2. Alternative agent and prophylactic platelet transfusion versus placebo or no treatment and prophylactic platelet transfusion

We will consider the following interventions:

- Experimental intervention: alternative agents

$\begin{array}{ll}\bigcirc & \text { artificial platelet substitutes } \\ \bigcirc & \text { platelet-poor plasma } \\ \text { rFVIIa } \\ \bigcirc & \text { fibrinogen } \\ & \text { TPO mimetics } \\ & \text { desmopressin }\end{array}$

There will be no restriction on the dose of alternative agents used.

- Comparator intervention:

O Comparison 1: alternative agent versus prophylactic platelet transfusion. The comparator is prophylactic platelet transfusions. Transfusion of platelet concentrates, prepared either from individual units of whole blood or by apheresis, and given prophylactically to prevent bleeding. Prophylactic platelet transfusions are typically given when blood platelet counts fall below a given trigger level. There will be no restriction on the dose or frequency of platelet transfusions, nor will there be a restriction on the transfusion trigger level, although we will take this information into account in the analysis where available.

O Comparison 2:alternative agent and prophylactic platelet transfusion versus placebo or no treatment and prophylactic platelet transfusion. The comparator is prophylactic platelet transfusions and placebo or no treatment. There will be no restriction on the dose or frequency of platelet transfusions used in addition to the alternative agents, but the dose of prophylactic platelet transfusions received and the platelet transfusion threshold at which they are given will be the same in both arms of the study. 


\section{Types of outcome measures}

Primary outcomes: Number and severity of bleeding episodes within 30 days from the start of the study:

- The number of patients with at least one bleeding episode.

- The total number of days on which bleeding occurred per patient.

- The number of patients with at least one episode of severe or life-threatening bleeding.

- Time to first bleeding episode from the start of the study.

\section{Secondary outcomes}

- Mortality (all-causes, secondary to bleeding, and secondary to infection) within 30 days and 90 days from the start of the study.

- Number of platelet transfusions per patient and number of platelet components per patient within 30 days from the start of the study.

- Number of red cell transfusions per patient and number of red cell components per patient within 30 days from the start of the study.

- Platelet transfusion interval within 30 days from the start of the study.

- Proportion of patients requiring additional interventions to stop bleeding (surgical, medical e.g. tranexamic acid, other blood products e.g. fresh frozen plasma (FFP), cryoprecipitate) within 30 days from the start of the study.

- Overall survival within 30 days, 90 days, and 180 days from the start of the study.

- Duration of thrombocytopenia within 30 days from the start of the study.

- Proportion of patients achieving complete remission within 30 days and 90 days from the start of the study.

- Total time in hospital within 30 days from the start of the study.

- Adverse effects of treatments (transfusion reactions, transfusion-transmitted infections, thromboembolism, development of platelet antibodies, development of platelet refractoriness, drug reactions) within 30 days and 90 days from the start of the study.

- Quality of life, as defined by the individual studies.

We will express all primary and secondary outcomes in the formats defined in the Measures of treatment effect section of this protocol if data are available. Two of our outcomes are of special note as we expect them to be only narrative reports. Firstly, assessment of quality of life will use the study's own measure as there is no definitive patient reported outcome measure for this patient group (Estcourt 2013b). Secondly, the platelet transfusion interval can be calculated in many different ways and it is unlikely that the exact methodology will be reported sufficiently to allow us to combine the data. 


\section{Search methods for identification of studies}

The Systematic Review Initiative (SRI) Information Specialist (CD) formulated entirely new search strategies for this review in collaboration with the Cochrane Haematological Malignancies Review Group.

\section{Electronic searches}

Bibliographic databases: We will search for randomised controlled trials in the following databases:

- CENTRAL (The Cochrane Library) (Appendix 1)

- MEDLINE (Ovid, 1946 to the present) (Appendix 2)

- PubMed (epublications only) (Appendix 3)

- Embase (Ovid, 1974 to the present) (Appendix 4)

- CINAHL (EBSCOhost, 1982 to the present) (Appendix 5)

- UKBTS/SRI Transfusion Evidence Library (www.transfusionevidencelibrary.com) (1980 to the present) (Appendix 6)

- Web of Science: Conference Proceedings Citation Index-Science (CPCI-S) (Thomson Reuters, 1990 to the present) (Appendix 7)

- Lilacs (BIREME/PAHO/WHO, 1982 to the present) (Appendix 8)

- IndMed (ICMR-NIC, 1985 to the present) (Appendix 9)

- $\quad$ KoreaMed (KAMJE, 1997 to the present) (Appendix 10)

- PakMediNet (2001 to the present) (Appendix 10)

As the search strategies have been rewritten, searches will be run from the earliest dates specified above and will not be updated from the original and updated searches in January 2002 (Stanworth 2004) and November 2011 (Estcourt 2012a). Searches in MEDLINE, Embase and CINAHL will be combined with adaptations of the Cochrane RCT search filters, as detailed in the Cochrane Handbook for Systematic Reviews of Interventions (Lefebvre 2011). All search strategies are presented in the Appendices as indicated.

Databases of ongoing trials: We will also search ClinicalTrials.gov (http:// clinicaltrials.gov/ct2/search) (Appendix 11), the WHO International Clinical Trials Registry (ICTRP) (http://apps.who.int/trialsearch/) (Appendix 11), the ISRCTN Register (http:// www.controlled-trials.com/isrctn/) (Appendix 12), the EU Clinical Trials Register (https:// www.clinicaltrialsregister.eu/ctr-search) (Appendix 13) and the Hong Kong Clinical Trials Register (http://www.hkclinicaltrials.com/) (Appendix 14) in order to identify ongoing trials.

\section{Searching other resources}

Handsearching of references: We will check references of all included trials, relevant review articles, and current treatment guidelines for further literature. These searches will be limited to the 'first generation' reference lists. 
Personal contacts: We will contact authors of relevant studies, study groups and experts worldwide known to be active in the field for unpublished material or further information on ongoing studies.

\section{Data collection and analysis}

Selection of studies: The selection of studies will be updated from the selection of studies performed for the previous version of this review (Estcourt 2012a).

Two independent review authors (LE, RG) will initially screen all electronically-derived citations and abstracts of papers identified by the review search strategy for relevance. Studies clearly irrelevant will be excluded at this stage.

The full texts of all potentially-relevant trials will then formally be assessed for eligibility by two independent review authors (LE, RG) against the criteria outlined above. All disagreements will be resolved by discussion with a third review author (SS). Further information will be sought from study authors if the article contains insufficient data to make a decision about eligibility. A study eligibility form will be designed for trials of platelet transfusion to help in the assessment of relevance, which will include ascertaining whether the participants had haematological disorders, and whether the two groups could be defined in the trial on the basis of use of an alternative agent to prophylactic platelet transfusions. The reasons why potentially-relevant studies failed to meet the eligibility criteria will be recorded.

Data extraction and management-The data extraction will be updated from the data extraction performed for the previous version of this review (Estcourt 2012a). This will include data extraction for all studies that have been included since the previous review and also for all review outcomes that were not part of the previous review (e.g. platelet transfusion interval, quality of life).

Two review authors (LE, RG) will conduct data extraction according to the guidelines proposed by the Cochrane Collaboration (Higgins 2011a). Potential disagreements between the review authors will be resolved by consensus. The review authors will not be blinded to names of authors, institutions, journals, or the outcomes of the trials. The data extraction forms have been piloted in the previous version of this review (Estcourt 2012a). Due to minor changes in the format the forms will piloted on a further study, thereafter the two authors (LE, RG) will extract data independently for all the studies. The following data will be extracted:

General information: Review author's name, date of data extraction, study ID, reference manager number, first author of study, author's contact address (if available), citation of paper, objectives of the trial.

Trial details: Trial design, location, setting, sample size, power calculation, treatment allocation, randomisation, blinding, inclusion and exclusion criteria, reasons for exclusion, comparability of groups, length of follow up, stratification, stopping rules described, statistical analysis, results, conclusion, and funding. 
Characteristics of participants: Age, gender, ethnicity, total number recruited, total number randomised, total number analysed, types of haematological disease, lost to followup numbers, drop outs (percentage in each arm) with reasons, protocol violations, previous treatments, current treatment, prognostic factors.

Interventions: Experimental and control interventions, type of platelet given, timing of intervention, dosage of platelet given, compliance to interventions, additional interventions given especially in relation to red cell transfusions, any differences between interventions.

Assessment of bias: Sequence generation, allocation concealment, blinding (participants, personnel, and outcome assessors), incomplete outcome data, selective outcome reporting, other sources of bias.

Outcomes measured: Number and severity of bleeding episodes. Mortality (all causes), and mortality due to bleeding. Proportion of patients achieving complete remission. Disease-free survival. Time in hospital. Number of platelet transfusions and platelet components. Number of red cell transfusions and red cell components. Platelet transfusion interval. Proportion of patients requiring additional interventions to stop bleeding (surgical, medical e.g. tranexamic acid, other blood products e.g. fresh frozen plasma (FFP), cryoprecipitate). Duration of thrombocytopenia. Quality of life. Adverse effects of treatments (e.g. transfusion reactions, transfusion-transmitted infections, thromboembolism, development of platelet antibodies or platelet refractoriness).

Both full-text versions and abstracts will be used to retrieve the data. Publications reporting on more than one trial will be extracted using one data extraction form for each trial. Trials reported in more than one publication will be extracted on one form only. If these sources do not provide sufficient information, we will contact the authors, study groups or companies for additional details.

Data entry into software will be done by one review author and will be checked for accuracy by a second review author.

Assessment of risk of bias in included studies-The 'Risk of bias' assessment will be updated from the 'Risk of bias' assessment performed for the previous version of this review (Estcourt 2012a).

Two review authors (LE, RG) will assess all newly-included studies for possible risk of bias (as described in the Cochrane Handbook (Higgins 2011c)). The assessment will include information about the design, conduct and analysis of the trial. Each criterion will be evaluated on a three-point scale: low risk of bias, high risk of bias, or unclear. To assess risk of bias, the following questions will be included in the risk of bias table for each included study:

- Was the allocation sequence adequately generated?

- Was allocation adequately concealed? 
- Was knowledge of the allocated intervention adequately prevented during the study (including an assessment of blinding of participants, personnel, and outcome assessors)?

- Were incomplete outcome data adequately addressed (for every outcome separately)?

- Are reports of the study free of selective outcome reporting?

- Was the study apparently free of other problems that could put it at risk of bias?

Measures of treatment effect-For dichotomous outcomes the number of outcomes in the treatment and control groups will be recorded and the treatment effect measures across individual studies will be estimated as the relative effect measures (relative risk (RR) with $95 \%$ confidence intervals (CI)).

For continuous outcomes, the mean and standard deviations will be recorded. For continuous outcomes measured using the same scale of the effect measure will be the mean difference (MD) with $95 \%$ confidence intervals, or the standardised mean difference (SMD) for outcomes measured using different scales. For time-to-event outcomes we will extract the hazard ratio (HR) from published data according to Parmar 1998 and Tierney 2007.

If appropriate, the number needed to treat to benefit (NNTB) with CIs and the number needed to treat to harm (NNTH) with CIs will be reported.

If the data available cannot be reported in any of the formats described above a narrative report will be performed.

Dealing with missing data-Missing data will be dealt with according to the recommendations in the Cochrane Handbook (Higgins 2011b). We will contact authors in order to obtain information that is missing or unclear in the published report.

In trials that include patients with haematological disorders as well as patients with solid tumours or non-malignant haematological disorders, we will extract data for the malignant haematology subgroup from the general trial data. If this cannot be done the trial author will be contacted.

Within an outcome, when there are missing data, the preferred analysis will be an intentionto-treat analysis (ITT). The number of patients lost to follow-up will be recorded for each trial.

Assessment of heterogeneity-If studies are considered sufficiently homogenous in their study design, we will conduct a meta-analysis and assess the statistical heterogeneity (Deeks 2011). Statistical heterogeneity of treatment effects between trials will be assessed using a $\mathrm{Chi}^{2}$ test with a significance level at $\mathrm{P}<0.1$. The $\mathrm{I}^{2}$ statistic will be used to quantify possible heterogeneity $\left(\mathrm{I}^{2}>50 \%\right.$ moderate heterogeneity, $\mathrm{I}^{2}>80 \%$ considerable heterogeneity). Potential causes of heterogeneity will be explored by sensitivity and subgroup analyses if possible. 
Assessment of reporting biases-We will explore meta-analyses with at least 10 trials for potential publication bias (small trial bias) by generating a funnel plot, and statistically test using a linear regression test. We will consider a $\mathrm{P}$ value of less than 0.1 significant for this test (Sterne 2011).

Data synthesis-Analyses will be performed according to the recommendations of the Cochrane Collaboration (Deeks 2011). Aggregated data will be used for analysis. For statistical analysis, we will enter data into Review Manager 2012.

Where meta-analysis is feasible, we will use the fixed-effect model for pooling the data. We will use the Mantel-Haenszel method for dichotomous outcomes, and the inverse variance method for continuous outcomes. The generic inverse variance method will be employed for time-to-event outcomes.

We will use the random-effects model for sensitivity analyses as part of the exploration of heterogeneity. If heterogeneity, as expressed by the $\mathrm{I}^{2}$, is found to be above $50 \%$, both the fixed-effect and random-effects models will be reported. If heterogeneity is found to be above $80 \%$, we will not perform a meta-analysis and results will be commented on as a narrative.

GRADEprofiler will be used to create 'Summary of findings' tables as suggested in the Cochrane Handbook (Schünemann 2011). This will include the number and severity of bleeding episodes within 30 days from the start of the study (number of patients with at least one bleeding episode; number of days on which bleeding occurred; number of patients with severe or life-threatening bleeding; time to first bleeding episode), number of platelet transfusions within 30 days from the start of the study, 30 day mortality and quality of life.

Separate meta-analyses will performed for each type of alternative agent.

Subgroup analysis and investigation of heterogeneity-Two subgroup analyses have been pre-specified prior to the previous version of this review; these are fever and patients' diagnostic and treatment subgroups. We will consider performing subgroup analysis on the following characteristics, if appropriate:

- $\quad$ Presence of fever $\left(>38^{\circ} \mathrm{C}\right)$

- Underlying disease

- Type of treatment (autologous HSCT, allogeneic HSCT, or chemotherapy alone)

- Age of the patient (paediatric, adults, older adults (> 60 years))

Meta-regression will be performed if subgroups contain more than 10 studies (Deeks 2011). Differences between subgroups will be compared using a random-effects model when the two subgroups are independent following the guidance in Chapter 9 of the Cochrane Handbook (Deeks 2011). If this is not possible then differences will be commented on as a narrative.

Investigation of heterogeneity between studies will also include, if appropriate: 
- Age of the study (as the type of platelet component has changed over the last 40 years)

- Different platelet component doses

- Different prophylactic platelet transfusion thresholds

Sensitivity analysis-Robustness of the overall results will be assessed by sensitivity analysis with respect to those trials deemed to be at high risk of bias.

For dichotomous data, we will assess the influence of participant drop-out, analysing separately RCTs with less than $20 \%$ drop-out, RCTs with $20 \%$ to 50\% drop-out and RCTs with greater than $50 \%$ drop-out.

We will use the random-effects model for sensitivity analyses as part of the exploration of heterogeneity.

\title{
ACKNOWLEDGEMENTS
}

\author{
We thank the editorial base of the Cochrane Haematological Malignancies Review Group. \\ We thank the authors on the previous review (Stanworth 2004): S Brunskill; N Heddle; S Hopewell; C Hyde; P \\ Rebulla.
}

\section{SOURCES OF SUPPORT}

Internal sources

- $\quad$ NHS Blood and Transplant, Research and Development, UK.

To support the work of the Systematic Review Initiative

External sources

- German Ministry of Education and Research (BMBF), Germany.

Towards support of the Cochrane Haematological Malignancies Group (Editorial support)

\section{Appendix 1. CENTRAL (The Cochrane Library) search strategy}

\#1 MeSH descriptor: [Hematologic Neoplasms] explode all trees

\#2 MeSH descriptor: [Leukemia] explode all trees

\#3 MeSH descriptor: [Lymphoma] explode all trees

\#4 MeSH descriptor: [Multiple Myeloma] explode all trees

\#5 MeSH descriptor: [Anemia, Aplastic] explode all trees

\#6 MeSH descriptor: [Bone Marrow Diseases] explode all trees

\#7 MeSH descriptor: [Thrombocytopenia] explode all trees

\#8 (thrombocytop* or leukemi* or leukaemi* or lymphoma* or aplastic anemia or aplastic anaemia or myelodysplas* or myeloproliferat* or multiple myeloma or plasma cell myeloma or thrombocythemi* or thrombocythaemi* or 
polycythemi* or polycythaemi* or myelofibros* or AML or CLL or CML or Hodgkin*)

\#9 ((haematolog* or hematolog* or blood or red cell* or white cell* or lymph* or marrow or platelet*) near/3 (malignan* or oncolog* or cancer* or neoplasm*))

\#10 MeSH descriptor: [Antineoplastic Agents] explode all trees

\#11 MeSH descriptor: [Stem Cell Transplantation] explode all trees

\#12 MeSH descriptor: [Bone Marrow Transplantation] this term only

\#13 MeSH descriptor: [Radiotherapy] explode all trees

\#14 (chemotherap* or radiotherap* or chemoradiotherap* or chemo-radiotherap* or stem cell* or bone marrow transplant*)

\#15 ((haematolog* or hematolog* or hemato-oncolog* or haemato-oncolog*) near/2 patients)

\#16 (malignan* or oncolog* or cancer*):ti

$\# 17 \# 1$ or \#2 or \#3 or \#4 or \#5 or \#6 or \#7 or \#8 or \#9 or \#10 or \#11 or \#12 or \#13 or $\# 14$ or \#15 or \#16

\#18 MeSH descriptor: [Factor VIIa] explode all trees

\#19 (factor viia or factor 7a or rfviia or fviia or novoseven* or novo seven* or eptacog* or proconvertin)

\#20 ((activated near/2 factor seven) or (activated near/2 factor vii) or (activated near/3 rfvii) or (activated near/2 fvii))

\#21 (factor seven or factor vii or factor 7):ti

\#22 MeSH descriptor: [Fibrinogen] explode all trees

\#23 ("fibrinogen NEXT concentrate*" or "factor I" OR haemocomplettan* OR octafibrin* OR riastap*)

\#24 ((platelet* or thrombocyte*) near/5 (substitute* or artificial*))

\#25 platelet-poor plasma*

\#26 MeSH descriptor: [Deamino Arginine Vasopressin] explode all trees

\#27 (desmopressin* or vasopressin deamino or nocutil or octim or minurin or deamino-8-d-arginine vasopressin or vasopressin 1-desamino-8-arginine or desmotabs or ddavp or ddavp or adiuretin or octostim or desmogalen)

\#28 MeSH descriptor: [Thrombopoietin] explode all trees and with qualifiers: [Administration \& dosage - AD, Adverse effects - AE, Therapeutic use - TU]

\#29 MeSH descriptor: [Recombinant Fusion Proteins] explode all trees and with qualifiers: [Administration \& dosage - AD, Adverse effects - AE, Therapeutic use - TU] 
\#30 MeSH descriptor: [Receptors, $\mathrm{Fc}$ ] explode all trees and with qualifiers: [Administration \& dosage - AD, Therapeutic use - TU]

\#31 MeSH descriptor: [Receptors, Thrombopoietin] explode all trees and with qualifiers: [Administration \& dosage - AD, Agonists - AG, Therapeutic use TU]

\#32 (eltrombopag* or promacta* or revolade* or romiplastin* or romiplostim* or nplate)

\#33 (amg531 or amg 531 or amg-531 or sb497115 or sb 497115 or sb-497115 or fab59 or fab 59 or fab-59 or AKR501 or AKR 501 or AKR-501 or YM477 or YM 477 or YM-477 or Peg-TPOmp*)

\#34 ((TPO or thrombopoietin) next (mimetic* or receptor agonist* or agonist* or agent*))

\#35 (( (haemosta* or hemosta* or antihaemorrhag* or antihemorrhag* or anti haemorrhag* or anti-hemorrhag*) near/5 (drug* or agent* or treat* or therap*)) or ((coagulat* or clotting) adj factor*))

\#36 \#18 OR \#19 OR \#20 OR \#21 OR \#22 OR \#23 OR \#24 OR \#25 OR \#26 OR \#27 OR \#28 OR \#29 OR \#30 OR \#31 OR \# 32 OR \#33 OR \#34 OR \#35

\#37 \#17 AND \#36

\section{Appendix 2. MEDLINE (Ovid) search strategy}

1. exp Hematologic Neoplasms/

2. exp Leukemia/or exp Lymphoma/

3. exp Multiple Myeloma/

4. exp Anemia, Aplastic/

5. exp Bone Marrow Diseases/

6. $\exp$ Thrombocytopenia/

7. (thrombocytop* or leukemi* or leukaemi* or lymphoma* or aplastic anemia or aplastic anaemia or myelodysplas* or myeloproliferat* or multiple myeloma or plasma cell myeloma or thrombocythemi* or thrombocythaemi* or polycythemi* or polycythaemi* or myelofibros* or AML or CLL or CML or Hodgkin*).tw.

8. ((haematolog* or hematolog* or blood or red cell* or white cell* or lymph* or marrow or platelet*) adj3 (malignan* or oncolog* or cancer* or neoplasm*)).tw.

9. exp Antineoplastic Agents/

10. exp Stem Cell Transplantation/or Bone Marrow Transplantation/or exp Radiotherapy/

11. (chemotherap* or radiotherap* or chemoradiotherap* or chemo-radiotherap* or stem cell* or bone marrow transplant*).tw. 
12. ((haematolog* or hematolog* or haemato-oncolog* or hemato-oncolog*) adj2 patients).tw.

13. (malignan* or oncolog* or cancer*).ti.

14. or/1-13

15. Factor VIIa/

16. (factor viia or factor 7a or rfviia or fviia or novoseven* or novo seven* or eptacog* or proconvertin).tw.

17. ((activated adj2 factor seven) or (activated adj2 factor vii) or (activated adj3 rfvii) or (activated adj2 fvii)).tw.

18. (factor seven or factor vii or factor 7).ti.

19. Fibrinogen/ad, ae, sd, tu, th

20. *Fibrinogen/

21. (fibrinogen concentrate* or factor I OR haemocomplettan* OR octafibrin* OR riastap*).tw.

22. ((platelet* or thrombocyte*) adj5 (substitute* or artificial*)).tw.

23. platelet-poor plasma*.tw.

24. *Deamino Arginine Vasopressin/

25. Deamino Arginine Vasopressin/ad, ae, st, tu, to

26. (desmopressin* or vasopressin deamino or nocutil or octim or minurin or deamino-8-d-arginine vasopressin or vasopressin 1-desamino-8-arginine or desmotabs or ddavp or ddavp or adiuretin or octostim or desmogalen).tw.

27. Thrombopoietin/ad, tu

28. Recombinant Fusion Proteins/ad, tu

29. Receptors, Fc/ad, tu

30. Receptors, Thrombopoietin/ad, ag, tu

31. (eltrombopag* or promacta* or revolade* or romiplastin* or romiplostim* or nplate or TPO*).tw.

32. (amg531 or amg 531 or amg-531 or sb497115 or sb 497115 or sb-497115 or fab59 or fab 59 or fab-59 or AKR501 or AKR 501 or AKR-501 or YM477 or YM 477 or YM-477 or Peg-TPOmp*).tw.

33. ((TPO or thrombopoietin) adj (mimetic* or receptor agonist* or agonist* or agent*)).tw.

34. (((haemosta* or hemosta* or antihaemorrhag* or antihemorrhag* or anti haemorrhag* or anti-hemorrhag*) adj5 (drug* or agent* or treat* or therap*)) or ((coagulat* or clotting) adj factor*)).tw. 
35. or/15-34

36. 14 and 35

\section{Appendix 3. PUBMED (epublications only)}

\#1 (thrombocytop* OR leukemi* OR leukaemi* OR lymphoma* OR aplastic anemia OR aplastic anaemia OR myelodysplas* OR myeloproliferat* OR multiple myeloma OR plasma cell myeloma OR thrombocythemi* OR thrombocythaemi* OR polycythemi* OR polycythaemi* OR myelofibros* OR Hodgkin*)

\#2 ((haematolog* OR hematolog* OR blood OR red cell* OR white cell* OR lymphom* OR marrow OR platelet*) AND (malignan* OR oncolog* OR cancer OR cancers OR neoplasm*))

\#3 \#1 OR \#2

\#4 ("factor viia"[TI] OR "factor 7a"[TI] OR rfviia[TI] OR fviia[TI] OR novoseven*[TI] OR “novo seven*”[TI] OR eptacog*[TI] OR proconvertin[TI] OR “fibrinogen concentrate*”[TI] OR "factor I"[TI] OR haemocomplettan[TI] OR octafibrin[TI] OR riastap[TI])

\#5 "activated factor seven"[TI] OR "activated factor vii"[TI] OR "activated rfvii" [TI] OR "activated fvii"[TI]

\#6 (factor seven[TI] OR factor vii[TI] OR factor 7[TI])

\#7 ((platelet* OR thrombocyte*) AND (substitute* OR artificial*))

\#8 (platelet-poor plasma* OR desmopressin* OR vasopressin deamino OR nocutil OR octim OR minurin OR deamino-8-d-arginine vasopressin OR vasopressin 1desamino-8-arginine OR desmotabs OR ddavp OR ddavp OR adiuretin OR octostim OR desmogalen)

\#9 (eltrombopag* OR promacta* OR revolade* OR romiplastin* OR romiplostim* OR nplate*)

\#10 (amg531 OR amg 531 OR amg-531 OR sb497115 OR sb 497115 OR sb-497115 OR fab59 OR fab 59 OR fab-59 OR AKR501 OR AKR 501 OR AKR-501 OR YM477 OR YM 477 OR YM-477 OR Peg-TPOmp*)

\#11 ((TPO OR thrombopoietin) AND (mimetic* OR receptor agonist* OR agonist* OR agent*))

\#12 ((haemosta* OR hemosta* OR antihaemorrhag* OR antihemorrhag* OR anti haemorrhag* OR anti-hemorrhag*) AND (drug OR drugs OR agent* OR treatment* OR therapy OR therapies)) OR (coagulat* factor OR clotting factor OR coagulat* factors OR clotting factors))

\#13 \#4 OR \#5 OR \#6 OR \#7 OR \#8 OR \#9 OR \#10 OR \#11 OR \#12

\#14 \#3 AND \#13 
\#15 (random* OR blind* OR control group* OR placebo OR controlled trial OR controlled study OR trials OR systematic review OR meta-analysis OR metaanalysis OR literature OR medline OR cochrane OR embase) AND (publisher[sb] NOT pubstatusnihms)

\#16 \#14 AND \#15

\section{Appendix 4. EMBASE (Ovid) search strategy}

1. Hematologic Malignancy/

2. Lymphoma/

3. NonHodgkin Lymphoma/

4. Hodgkin Disease/

5. exp Myeloproliferative Disorder/

6. exp Aplastic Anemia/

7. $\exp$ Thrombocytopenia/

8. (thrombocytop* or leukemi* or leukaemi* or lymphoma* or aplastic anemia or aplastic anaemia or myelodysplas* or myeloproliferat* or multiple myeloma or plasma cell myeloma or thrombocythemi* or thrombocythaemi* or polycythemi* or polycythaemi* or myelofibros* or AML or CLL or CML or Hodgkin*).tw.

9. ((haematolog* or hematolog* or blood or red cell* or white cell* or lymph* or marrow or platelet*) adj3 (malignan* or oncolog* or cancer* or neoplasm*)).tw.

10. exp Chemotherapy/

11. exp Stem Cell Transplantation/

12. exp Bone Marrow Transplantation/

13. exp Radiotherapy/

14. (chemotherap* or radiotherap* or chemoradiotherap* or chemo-radiotherap* or stem cell* or bone marrow transplant*).tw.

15. ((haematolog* or hematolog* or haemato-oncolog* or hemato-oncolog*) adj2 patients).tw.

16. (malignan* or oncolog* or cancer*).ti.

17. or/1-16

18. Factor VIIa/

19. (factor viia or factor 7a or rfviia or fviia or novoseven* or novo seven* or eptacog* or proconvertin).tw.

20. ((activated adj2 factor seven) or (activated adj2 factor vii) or (activated adj3 rfvii) or (activated adj2 fvii)).tw. 
21. (factor seven or factor vii or factor 7).ti.

22. Fibrinogen/ae, ct, ad, cb, cm, cr, dv, do, dt, to, iv, pa, sc, th

23. Fibrinogen Concentrate/

24. (fibrinogen concentrate* or factor I or haemocomplettan* OR octafibrin* OR riastap*).tw.

25. ((platelet* or thrombocyte*) adj5 (substitute* or artificial*)).tw.

26. platelet-poor plasma*.tw.

27. *Desmopressin/

28. Desmopressin/ad, ae, dt

29. (desmopressin* or vasopressin deamino or nocutil or octim or minurin or deamino-8-d-arginine vasopressin or vasopressin 1-desamino-8-arginine or desmotabs or ddavp or ddavp or adiuretin or octostim or desmogalen).tw.

30. *Thrombopoietin Receptor/

31. Eltrombopag/

32. Romiplostim/

33. (eltrombopag* or promacta* or revolade* or romiplastin* or romiplostim* or nplate*).tw.

34. (amg531 or amg 531 or amg-531 or sb497115 or sb 497115 or sb-497115 or fab59 or fab 59 or fab-59 or AKR501 or AKR 501 or AKR-501 or YM477 or YM 477 or YM-477 or Peg-TPOmp*).tw.

35. ((TPO or thrombopoietin) adj (mimetic* or receptor agonist* or agonist*)).tw.

36. (((haemosta* or hemosta* or antihaemorrhag* or antihemorrhag* or anti haemorrhag* or anti-hemorrhag*) adj5 (drug* or agent* or treat* or therap*)) or ((coagulat* or clotting) adj factor*)).tw.

37. or $/ 18-36$

38. 17 and 37

\section{Appendix 5. CINAHL (EBSCOhost) search strategy}

S1 (MH "Hematologic Neoplasms+")

S2 (MH Leukemia+)

S3 (MH Lymphoma+)

S4 (MH "Multiple Myeloma+")

S5 (MH “Anemia, Aplastic+")

S6 (MH "Bone Marrow Diseasest") 
S7 (MH Thrombocytopenia+)

S8 (thrombocytop* or leukemic* or leukaemia* or lymphoma* or aplastic anemia or aplastic anaemia or myelodysplas* or myeloproliferat* or multiple myeloma or plasma cell myeloma or thrombocythemi* or thrombocythaemi* or polycythemi* or polycythaemi* or myelofibros* or AML or CLL or CML or Hodgkin*)

S9 ((haematolog* or hematolog* or blood or red cell* or white cell* or lymph* or marrow or platelet*) N3 (malignan* or oncolog* or cancer* or neoplasm*))

S10 (MH “Antineoplastic Agents+")

S11 (MH "Hematopoietic Stem Cell Transplantation")

S12 (MH "Bone Marrow Transplantation")

S13 (MH Radiotherapy+)

S14 (chemotherap* or radiotherap* or chemoradiotherap* or chemo-radiotherap* or stem cell* or bone marrow transplant*)

S15 ((haematolog* or hematolog* or haemato-oncolog* or hemato-oncolog*) N2 patients)

S16 TI (malignan* or oncolog* or cancer*)

S17 S1 OR S2 OR S3 OR S4 OR S5 OR S6 OR S7 OR S8 OR S9 OR S10 OR S11 OR S12 OR S13 OR S14 OR S15 OR S16

\section{S18 (MH “BLOOD COAGULATION FACTORS+")}

S19 (factor viia or factor 7a or rfviia or fviia or novoseven* or novo seven* or eptacog* or proconvertin or fibrinogen concentrate* or factor I OR haemocomplettan* OR octafibrin* OR riastap*)

S20 ((activated N2 factor seven) or (activated N2 factor vii) or (activated N3 rfvii) or (activated $\mathrm{N} 2$ fvii))

S21 TI (factor seven or factor vii or factor 7)

S22 ((platelet* or thrombocyte*) N5 (substitute* or artificial*))

S23 platelet-poor plasma*

S24 (MH Desmopressin)

S25 (desmopressin* or vasopressin deamino or nocutil or octim or minurin or deamino-8-d-arginine vasopressin or vasopressin 1-desamino-8-arginine or desmotabs or ddavp or ddavp or adiuretin or octostim or desmogalen)

S26 (MH "Benzoic Acids Therapeutic Use")

S27 (MH "Receptors, Cell Surface Therapeutic Use")

S28 (eltrombopag* or promacta* or revolade* or romiplastin* or romiplostim* or nplate*) 
S29 (amg531 or amg 531 or amg-531 or sb497115 or sb 497115 or sb-497115 or fab59 or fab 59 or fab-59 or AKR501 or AKR 501 or AKR-501 or YM477 or YM 477 or YM-477 or Peg-TPOmp*)

S30 ((TPO or thrombopoietin) W1 (mimetic* or receptor agonist* or agonist* or agent $\left.\left.^{*}\right)\right)$

S31 (( (haemosta* or hemosta* or antihaemorrhag* or antihemorrhag* or anti haemorrhag* or anti-hemorrhag*) N5 (drug* or agent* or treat* or therap*)) or ((coagulat* or clotting) W1 factor*))

S32 S18 OR S19 OR S20 OR S21 OR S22 OR S23 OR S24 OR S25 OR S26OR S27 OR S28 OR S29 OR S30 OR S31

S33 S170 AND S32

\section{Appendix 6. TRANSFUSION EVIDENCE LIBRARY search strategy}

\#1 HAEMATOLOGICAL MALIGNANCIES [Keywords]

\#2 (thrombocytop* OR leukemi* OR leukaemi* OR lymphoma* OR aplastic anemia OR aplastic anaemia OR myelodysplas* OR myeloproliferat* OR multiple myeloma OR plasma cell myeloma OR thrombocythemi* OR thrombocythaemi* OR polycythemi* OR polycythaemi* OR myelofibros* OR Hodgkin*)

\#3 ((haematolog* OR hematolog* OR blood OR red cell* OR white cell* OR lymphom* OR marrow OR platelet*) AND (malignan* OR oncolog* OR cancer OR cancers OR neoplasm*))

\#4 \#1 OR \#2 OR \#3

\#5 FACTOR VIIA [Keywords]

\#6 ("factor viia” OR "factor 7a" OR rfviia OR fviia OR novoseven* OR "novo seven*" OR eptacog* OR proconvertin OR "fibrinogen concentrate*" OR "factor I" OR haemocomplettan* OR octafibrin* OR riastap* OR "activated factor seven" OR "activated factor vii” OR "activated rfvii” OR “activated fvii" OR “factor seven” OR “factor vii” OR “factor 7”) [In Title]

\#7 ((platelet* OR thrombocyte*) AND (substitute* OR artificial*))

\#8 (platelet-poor plasma* OR desmopressin* OR vasopressin deamino OR nocutil OR octim OR minurin OR deamino-8-d-arginine vasopressin OR vasopressin 1desamino-8-arginine OR desmotabs OR ddavp OR ddavp OR adiuretin OR octostim OR desmogalen OR eltrombopag* OR promacta* OR revolade* OR romiplastin* OR romiplostim* OR nplate*)

\#9 (amg531 OR amg 531 OR amg-531 OR sb497115 OR sb 497115 OR sb-497115 OR fab59 OR fab 59 OR fab-59 OR AKR501 OR AKR 501 OR AKR-501 OR YM477 OR YM 477 OR YM-477 OR Peg-TPOmp*)

\#10 ((TPO OR thrombopoietin) AND (mimetic* OR agonist* OR agent*)) 
\#11 ((haemosta* OR hemosta* OR antihaemorrhag* OR antihemorrhag* OR anti haemorrhag* OR anti-hemorrhag*) AND (drug OR drugs OR agent* OR treatment* OR therapy OR therapies))

\#12 “coagulation factor" OR "clotting factor" OR "coagulation factors" OR "clotting factors"

\#13 \#5 OR \#6 OR \#7 OR \#8 OR \#9 OR \#10 OR \#11 OR \#12

\#14 \#4 AND \#13

\section{Appendix 7. Web of Science (CPCI-S) search strategy}

((“factor viia" OR "factor 7a" OR rfviia OR fviia OR novoseven OR "novo seven" OR eptacog OR proconvertin OR "fibrinogen concentrate" OR "factor I" OR haemocomplettan OR octafibrin OR riastap OR "activated factor seven" OR "activated factor vii" OR "activated rfvii" OR "activated fvii" OR "factor seven" OR "factor vii” OR "factor 7" OR "platelet-poor plasma" OR desmopressin OR eltrombopag OR promacta OR revolade OR romiplastin OR romiplostim OR nplate OR "thrombopoietin receptor*" OR "thrombopoietin agonist*” OR "thrombopoietin mimetic*”) AND (thrombocytop* OR leukemi* OR leukaemi* OR lymphoma* OR aplastic anemia OR aplastic anaemia OR myelodysplas* OR myeloproliferat* OR myeloma OR thrombocythemi* OR thrombocythaemi* OR polycythemi* OR polycythaemi* OR myelofibros* OR Hodgkin* OR haematological OR hematological)) [in Title]

AND (randomized OR randomised OR randomly) [in Title]

\section{Appendix 8. LILACS search strategy}

((“factor viia" OR "factor 7a" OR rfviia OR fviia OR novoseven OR "novo seven" OR eptacog OR proconvertin OR "fibrinogen concentrate" OR "factor I" OR haemocomplettan OR octafibrin OR riastap OR "activated factor seven" OR "activated factor vii" OR “activated rfvii” OR "activated fvii” OR "factor seven” OR "factor vii” OR "factor 7" OR "platelet-poor plasma" OR desmopressin OR eltrombopag OR promacta OR revolade OR romiplastin OR romiplostim OR nplate OR "thrombopoietin receptor\$" OR "thrombopoietin agonist\$” OR “thrombopoietin mimetic\$”) AND (thrombocytop\$ OR leukemi\$ OR leukaemi\$ OR lymphoma OR aplastic anemia OR aplastic anaemia OR myelodysplas\$ OR myeloproliferat\$ OR myeloma OR thrombocythemi\$ OR thrombocythaemi\$ OR polycythemi\$ OR polycythaemi\$ OR myelofibros\$ OR Hodgkin\$ OR haematological OR hematological)) AND db:(“LILACS”) AND type_of_study:(“clinical_trials” OR "systematic_reviews")

\section{Appendix 9. INDMED search strategy}

((factor viia OR factor 7\$ OR rfvii\$ OR fvii\$ OR factor seven OR factor vii OR novoseven OR novo seven OR eptacog OR proconvertin OR fibrinogen OR factor I OR haemocomplettan OR octafibrin OR riastap OR platelet-poor plasma OR desmopressin OR eltrombopag OR promacta OR revolade OR romiplastin OR romiplostim OR nplate OR 
thrombopoietin receptor\$ OR thrombopoietin agonist\$ OR thrombopoietin mimetic\$) AND (thrombocytop\$ OR leukemi\$ OR leukaemi\$ OR lymphoma \$ OR aplastic OR myelodysplas \$ OR myeloproliferat\$ OR myeloma OR thrombocythemi\$ OR thrombocythaemi\$ OR polycyth\$ OR myelofibros\$ OR Hodgkin \$ OR haematological OR hematological OR haematopoietic OR hematopoietic) AND (random\$ OR blind\$ OR trial\$ OR control\$))

\title{
Appendix 10. KOREAMED \& PAKMEDINET search strategy
}

\author{
"factor viia"[ALL] AND "Randomized Controlled Trial” [PT] \\ novoseven[ALL] AND "Randomized Controlled Trial" [PT] \\ fibrinogen[ALL] AND "Randomized Controlled Trial” [PT] \\ haemocomplettan[ALL] AND "Randomized Controlled Trial” [PT] \\ octafibrin[ALL] AND “Randomized Controlled Trial” [PT] \\ riastap[ALL] AND "Randomized Controlled Trial” [PT] \\ "platelet-poor plasma" [ALL] AND "Randomized Controlled Trial" [PT] \\ desmopressin[ALL] AND "Randomized Controlled Trial" [PT] \\ eltrombopag[ALL] AND “Randomized Controlled Trial” [PT] \\ promacta[ALL] AND "Randomized Controlled Trial” [PT] \\ revolade[ALL] AND "Randomized Controlled Trial” [PT] \\ romiplostim[ALL] AND "Randomized Controlled Trial” [PT] \\ nplate[ALL] AND “Randomized Controlled Trial” [PT] \\ "thrombopoietin receptor agonist*”[ALL] "Randomized Controlled Trial” [PT]
}

\section{Appendix 11. ClinicalTrials.gov \& ICTRP search strategy}

Search Terms/Title: randomized OR randomised

Conditions: hematological neoplasm OR hematological malignancies OR leukemia OR lymphoma OR thrombocytopenia OR multiple myeloma OR aplastic anemia OR thrombocythemia OR polycythemia OR myelofibrosis OR hodgkins disease Intervention: factor viia OR rFVIIa OR recombinant factor vii OR activated factor vii OR desmopressin OR eptacog OR proconvertin OR fibrinogen concentrate OR haemocomplettan OR octafibrin OR riastap OR platelet-poor plasma OR eltrombopag OR promacta OR revolade OR romiplostim OR thrombopoietin receptor agonist

\section{Appendix 12. ISRCTN search strategy}

(hematological OR haematological OR leukemi\% OR leukaemi\% OR lymphoma OR thrombocytopenia\% OR myeloma OR aplastic OR thrombocythemia OR polycythemia OR 
myelofibrosis OR hodgkin\%) AND (factor viia OR rFVIIa OR factor vii OR novoseven OR desmopressin) AND random\%

(hematological OR haematological OR leukemi\% OR leukaemi\% OR lymphoma OR thrombocytopenia\% OR myeloma OR aplastic OR thrombocythemia OR polycythemia OR myelofibrosis OR hodgkin\%) AND (eptacog OR proconvertin OR fibrinogen concentrate OR haemocomplettan) AND random $\%$

(hematological OR haematological OR leukemi\% OR leukaemi\% OR lymphoma OR thrombocytopenia\% OR myeloma OR aplastic OR thrombocythemia OR polycythemia OR myelofibrosis OR hodgkin\%) AND (octafibrin OR riastap OR platelet-poor plasma OR eltrombopag) AND random\%

(hematological OR haematological OR leukemi\% OR leukaemi\% OR lymphoma OR thrombocytopenia\% OR myeloma OR aplastic OR thrombocythemia OR polycythemia OR myelofibrosis OR hodgkin\%) AND (promacta OR revolade OR romiplostim OR nplate OR receptor agonist) AND random\%

\section{Appendix 13. EU Clinical Trials Register search strategy}

(hematological OR haematological OR leukemi* OR leukaemi* OR lymphoma OR thrombocytopeni* OR myeloma OR aplastic OR thrombocythemia OR polycythemia OR myelofibrosis OR hodgkin*) AND (novoseven OR rFVIIa OR desmopressin OR eptacog OR proconvertin* OR fibrinogen OR haemocomplettan* OR octafibrin* OR riastap* OR eltrombopag* OR promacta* OR revolade* OR romiplostim* OR nplate* OR thrombopoietin) AND random*

OR

factor viia AND random*

OR

recombinant factor vii AND random*

OR

platelet-poor plasma AND random*

\section{Appendix 14. Hong Kong Clinical Trials Registry search strategy}

Disease Group: Blood and blood-forming organs

Title: randomized OR randomised

\section{DECLARATIONS OF INTEREST}

Lise Estcourt: none declared. 
Richard Gregg: none declared.

Simon Stanworth: none declared.

Carolyn Doree: none declared.

Marialena Trivella: none declared.

Sally Hopewell: none declared.

Mike Murphy: none declared.

Alan Tinmouth: none declared.

\section{Additional references}

* Indicates the major publication for the study

Barnhart 1983 . Barnhart MI, Chen S, Lusher JM. DDAVP: Does the drug have a direct effect on the vessel wall? Thrombosis Research. 1983; 31(2):239-52. [PubMed: 6415852]

BCSH 2003 . British Committee for Standards in Haematology (BCSH). Guidelines for the use of platelet transfusions. British Journal of Haematology. 2003; 122:10-23. [PubMed: 12823341]

BCSH 2004 . British Committee for Standards in Haematology (BCSH). Transfusion guidelines for neonates and older children. British Journal of Haematology. 2004; 124(4):433-53. [PubMed: 14984493]

Benson 2009 . Benson AB, Moss M, Silliman CC. Transfusion-related acute lung injury (TRALI): a clinical review with emphasis on the critically ill. British Journal of Haematology. 2009; 147(4): 431-43. [PubMed: 19663827]

Blajchman 2008 . Blajchman MA, Slichter SJ, Heddle NM, Murphy MF. New strategies for the optimal use of platelet transfusions. Hematology (American Society of Hematology Education Program). 2008; 1:198-204. DOI: 10.1182/asheducation-2008.1.198.

Blumberg 2009 . Blumberg N, Spinelli SL, Francis CW, Taubman MB, Phipps RP. The platelet as an immune cell - CD40 ligand and transfusion immune modulation. Immunology Research. 2009; 45:251-60.

Board 2009 . The Board of the German Medical Association on the Recommendation of the Scientific Advisory Board. Platelet concentrates. Cross-sectional guidelines for therapy with blood components and plasma derivatives. Transfusion Medicine and Hemotherapy. 2009; 36:372-82. [PubMed: 21245968]

Bolton-Maggs 2012 . Cohen, H.; Serious Hazards of Transfusion (SHOT) Steering Group. The 2011 Annual SHOT Report. Bolton-Maggs, PHB., editor. Serious Hazards of Transfusion (SHOT); 2012.

Burnett 2011 . Burnett AK, Hills RK, Milligan D, Kjeldsen L, Kell J, Russell NH, et al. Identification of patients with acute myeloblastic leukemia who benefit from the addition of gemtuzumab ozogamicin: Results of the MRC AML15 trial. Journal of Clinical Oncology. 2011; 29(4):369-77. [PubMed: 21172891]

Butler 2013 . Butler C, Doree C, Estcourt LJ, Trivella M, Hopewell S, Brunskill SJ, et al. Pathogenreduced platelets for the prevention of bleeding. Cochrane Database of Systematic Reviews. 2013; (3) DOI: 10.1002/14651858.CD009072.

Cameron 2007 . Cameron B, Rock G, Olberg B, Neurath D. Evaluation of platelet transfusion triggers in a tertiary-care hospital. Transfusion. 2007; 47(2):206-11. [PubMed: 17302765]

Cancer Research UK 2013 . Cancer Research UK. [Accessed 14/02/2013] Percentage change in european age-standardised three year average incidence rates, males, UK, 1991-2001 and 2008-2010. Cancer Research UK statistics. at http://www.cancerresearchuk.org/cancer-info/ cancerstats/ 
CDC 2012 . CDC (Center for Disease Control). United States Cancer Statistics. National Program of Cancer Registries (NPCR); 2012. [Accessed 14/02/2013]

Coleman 2004 . Coleman MP, Rachet B, Woods LM, Mitry E, Riga M, Cooper N, et al. Trends and socioeconomic inequalities in cancer survival in England and Wales up to 2001. British Journal of Cancer. 2004; 90(7):1367-73. [PubMed: 15054456]

Cook 2004 . Cook RJ, Heddle NM, Rebulla P, Sigouin CS, Webert KE. Methods for the analysis of bleeding outcomes in randomized trials of platelet transfusion triggers. Transfusion. 2004; 44:1135-42. [PubMed: 15265116]

De la Serna 2008 . De la Serna J, Montesinos P, Vellenga E, Rayon C, Parody R, Leon A, et al. Causes and prognostic factors of remission induction failure in patients with acute promyelocytic leukemia treated with all-trans retinoic acid and idarubicin. Blood. 2008; 111(7):3395-402. [PubMed: 18195095]

Deeks 2011 . Deeks, JJ.; Higgins, JPT.; Altman, DG.; Higgins, JPT.; Green, S., editors. Cochrane Handbook for Systematic Reviews of Interventions. The Cochrane Collaboration; 2011. Chapter 9: Analysing data and undertaking meta-analyses. Version 5.1.0 (updated March 2011)Available from www.cochrane-handbook.org

Doshi 2012 . Doshi N, Orje JN, Molins B, Smith JW, Mitragotri S, Ruggeri ZM. Platelet mimetic particles for targeting thrombi in flowing blood. Advanced Materials. 2012; 24(28):3864-9. [PubMed: 22641451]

Duke 1910 . Duke WW. The relation of blood platelets to hemorrhagic disease. Description of a method for determining the bleeding time and coagulation time and report of 3 cases of hemorrhagic disease relieved by transfusion. Journal of the American Medical Association. 1910; 55:1185-92.

Estcourt 2011 . Estcourt LJ, Stanworth SJ, Murphy MF. Platelet transfusions for patients with haematological malignancies: who needs them? British Journal of Haematology. 2011; 154(4): 425-40. [PubMed: 21615375]

Estcourt 2012b . Estcourt LJ, Birchall J, Lowe D, Grant-Casey J, Rowley M, Murphy MF. Platelet transfusions in haematology patients: are we using them appropriately? Vox Sanguinis. 2012; 103(4):284-93. [PubMed: 22775395]

Estcourt 2013a . Estcourt LJ, Heddle N, Kaufman RM, McCullough J, Murphy MF, Slichter S, et al. BEST (Biomedical Excellence for Safer Transfusion) Collaborative. Differences in the methods of assessing and analysing bleeding outcomes in platelet transfusion trials. Transfusion. 2013; 53(7):1531-43. [PubMed: 23305609]

Estcourt 2013b . Estcourt LJ, Pinchon D, Symington E, Kelly AM, Doree C, Brunskill S, et al. Does bleeding affect patient reported outcome measures in patients with myelodysplasia or hematologic malignancies: a systematic review. Transfusion. 2013 [Early on-line publication]. [DOI: 10.1111/trf.12441].

Fielding 2007 . Fielding AK, Richards SM, Chopra R, Lazarus HM, Litzow MR, Buck G, et al. Outcome of 609 adults after relapse of acute lymphoblastic leukemia (ALL); an MRC UKALL12/ECOG 2993 study. Blood. 2007; 109(3):944-50. PUBMED: 17032921. [PubMed: 17032921]

Gratwohl 2010 . Gratwohl A, Baldomero H, Aljurf M, Pasquini MC, Bouzas LF, Yoshimi A, et al. Hematopoietic stem cell transplantation: a global perspective. JAMA. 2010; 303(16):1617-24. DOI: 10.1001/jama.2010.491. [PubMed: 20424252]

Greeno 2007 . Greeno E, McCullough J, Weisdorf D. Platelet utilisation and the transfusion trigger: a prospective analysis. Transfusion. 2007; 72(2):201-5. [PubMed: 17302764]

Heddle 2003 . Heddle NM, Cook RJ, Webert KE, Sigouin C, Rebulla P. Methodologic issues in the use of bleeding as an outcome in transfusion medicine studies. Transfusion. 2003; 43:742-52. [PubMed: 12757525]

Heddle 2008 . Heddle NM, Arnold DM, Boye D, Webert KE, Resz I, Dumont LJ. Comparing the efficacy and safety of apheresis and whole blood-derived platelet transfusions: a systematic review. Transfusion. 2008; 48(7):1447-58. [PubMed: 18482183]

Heddle 2009a . Heddle NM, Cook RJ, Tinmouth A, Kouroukis CT, Hervig T, Klapper E, et al. A randomized controlled trial comparing standard and low dose strategies for transfusion of 
platelets (SToP) to patients with thrombocytopenia. Blood. 2009; 113(7):1564-73. [PubMed: 19109560]

Heddle 2009b . Heddle, NM.; Webbert, K. Investigation of acute transfusion reactions. In: Murphy, MF.; Pamphilion, DH., editors. Practical Transfusion Medicine. 4th Edition. Blackwell; 2009. p. 63-89.

Higby 1974 . Higby DJ, Cohen E, Holland JF, Sinks L. The prophylactic treatment of thrombocytopenic leukemic patients with platelets: a double blind study. Transfusion. 1974; 14:440-5. [PubMed: 4607226]

Higgins 2011a . Higgins, JPT.; Deeks, JJ.; Higgins, JPT.; Green, S., editors. Cochrane Handbook for Systematic Reviews of Interventions. The Cochrane Collaboration; 2011. Chapter 7: Selecting studies and collecting data. Version 5.1.0 (updated March 2011)Available from www.cochranehandbook.org

Higgins 2011b . Higgins, JPT.; Deeks, JJ.; Altman, DG.; Higgins, JPT.; Green, S., editors. Cochrane Handbook for Systematic Reviews of Interventions. The Cochrane Collaboration; 2011. Chapter 16: Special topics in Statistics. Version 5.1.0 (updated March 2011)Available from www.cochrane-handbook.org

Higgins 2011c . Higgins, JPT.; Altman, DG.; Sterne, JAC.; Higgins, JPT.; Green, S., editors. Cochrane Handbook for Systematic Reviews of Interventions. The Cochrane Collaboration; 2011. Chapter 8: Assessing risk of bias in included studies. Version 5.1.0 (updated March 2011)Available from www.cochrane-handbook.org

Knowles 2011 . Cohen, H.; Serious Hazards of Transfusion (SHOT) Steering Group. The 2010 Annual SHOT Report. Knowles, S., editor. Serious Hazards of Transfusion (SHOT); 2011.

Koreth 2004 . Koreth R, Weinert C, Weisdorf DJ, Key NS. Measurement of bleeding severity: a critical review. Transfusion. 2004; 44:605-17. [PubMed: 15043580]

Kuter 2010 . Kuter DJ. Biology and chemistry of thrombopoietic agents. Seminars in Hematology. 2010; 47(3):243-8. [PubMed: 20620435]

Lefebvre 2011 . Lefebvre, C.; Manheimer, E.; Glanville, J.; Chapter, 6. Searching for studies. In: Higgins, JPT.; Green, S., editors. Cochrane Handbook for Systematic Reviews of Interventions. The Cochrane Collaboration; 2011. Version 5.1.0 (updated March 2011)Available from www.cochrane-handbook.org

Manco-Johnson 2009 . Manco-Johnson MJ, Dimichele D, Castaman G, Fremann S, Knaub S, Kalina $\mathrm{U}$, et al. Pharmacokinetics and safety of fibrinogen concentrate. Journal of Thrombosis and Haemostasis. 2009; 7(12):2064-9. [PubMed: 19804533]

Mannucci 1997 . Mannucci PM. Desmopressin (DDAVP) in the treatment of bleeding disorders: the first 20 years. Blood. 1997; 90(7):2515-21. [PubMed: 9326215]

Miao 2012 . Miao M, Wu DP, Cao XS, Dong WM, Wang B, Ou YJ, et al. Clinical study on platelet engraftment by thrombopoietin in patients with hematological malignancies after allogeneic hematopoietic stem cell transplantation. Zhonghua Xue Ye Xue Za Zhi. 2012; 33(5):362-5. [PubMed: 22781792]

Murphy 1982 . Murphy S, Litwin S, Herring LM, Koch P, Remischovky J, Donaldson MH, et al. Indications for platelet transfusion in children with acute leukemia. American Journal of Hematology. 1982; 12:347-56. [PubMed: 6981349]

NBA 2012 . National Blood Authority. The National Blood Authority's Patient Blood Management Guideline: Module 3 - Medical. National Blood Authority; 2012.

NICE 2010 . NICE. Eltrombopag for the treatment of chronic immune (idiopathic) thrombocytopenic purpura TA205. National Institute for Clinical Excellence; 2010.

NICE 2011 . NICE. Romiplostim for the treatment of chronic immune (idiopathic) thrombocytopenic purpura TA221. National Institute for Clinical Excellence; 2011.

Nishiya 2002 . Nishiya T, Kainoh M, Murata M, Handa M, Ikeda Y. Reconstitution of adhesive properties of human platelets in liposomes carrying both recombinant glycoproteins Ia/IIa and Iba under flow conditions: specific synergy of receptor-ligand interactions. Blood. 2002; 100(1): 136-42. [PubMed: 12070018] 
Okamura 2009a . Okamura Y, Fukui Y, Kabata K, Suzuki H, Handa M, Ikeda Y, et al. Novel platelet substitutes: disk-shaped biodegradable nanosheets and their enhanced effects on platelet aggregation. Bioconjugate Chemistry. 2009; 20:1958-65. [PubMed: 19788180]

Okamura 2009b . Okamura Y, Takeoka S, Eto K, Maekawa I, Fujie T, Maruyama H, et al. Development of fibrinogen gamma-chain peptide-coated, adenosine diphosphate-encapsulated liposomes as a synthetic platelet substitute. Journal of Thrombosis and Haemostasis. 2009; 7(3): 470-7. [PubMed: 19143920]

ONS 2012 . ONS. Cancer incidence and mortality tables and charts. Office of National Statistics; 2012. [Accessed 14/02/2013]

Parmar 1998 . Parmar MK, Torri V, Stewart L. Extracting summary statistics to perform metaanalyses of the published literature for survival endpoints. Statistics in Medicine. 1998; 17(24): 2815-34. [PubMed: 9921604]

Passweg 2012 . Passweg JR, Baldomero H, Gratwohl A, Bregni M, Cesaro S, Dreger P, et al. The EBMT activity survey: 1990-2010. Bone Marrow Transplant. 2012; 47(7):906-23. [PubMed: 22543746]

Patel 2009 . Patel B, Kirkland K, Szydlo R, Pearce R, Clark R, Craddock C, et al. Favorable outcomes with alemtuzumab-conditioned unrelated donor stem cell transplantation in adults with high-risk Philadelphia chromosome-negative acute lymphoblastic leukemia in first complete remission. Haematologica. 2009; 94:1399-406. [PubMed: 19648167]

Pavenski 2013 . Pavenski K, Rebulla P, Duquesnoy R, Saw CL, Slichter SJ, Tanael S, et al. International Collaboration for Guideline Development, Implementation. Evaluation for Transfusion Therapies, Collaborators. Efficacy of HLA-matched platelet transfusions for patients with hypoproliferative thrombocytopenia: a systematic review. Transfusion. 2013 Epub:ahead of print. [DOI: 10.1111/trf.12175].

Pearce 2011 . Pearce S, Rowe GP, Field SP. Screening of platelet for bacterial contamination at the Welsh Blood Service. Transfusion Medicine. 2011; 21(1):25-32. [PubMed: 20854460]

Pendry 2011 . Pendry K, Davies T. An audit of use and wastage in the north west of England and North Wales: where have all the platelets gone? Blood and Transplant Matters. 2011; 34:17-9.

Popovsky 1985 . Popovsky MA, Moore SB. Diagnostic and pathogenetic considerations in transfusion-related acute lung injury. Transfusion. 1985; 25:573-7. [PubMed: 4071603]

Rachet 2009 . Rachet B, Maringe C, Nur U, Quaresma M, Shah A, Woods LM, et al. Populationbased cancer survival trends in England and Wales up to 2007: an assessment of the NHS cancer plan for England. The Lancet Oncology. 10; 4:351-69. [PubMed: 12788407]

Review Manager 2012 . The Nordic Cochrane Centre. Review Manager (RevMan). 5.2. The Cochrane Collaboration; Copenhagen: 2012.

Rysler 2010 . Rysler C, Stoffel N, Buser A, Gratwohl A, Tsakiris DA, Stern M. Effect of betablockers, Ca2+antagonists, and benzodiazepines on bleeding incidence in patients with chemotherapy induced thrombocytopenia. Platelets. 2010; 21(1):77-83. [PubMed: 19929239]

Sakariassen 1984 . Sakariassen KS, Cattaneo M, van der Berg A, Ruggeri ZM, Sixma JJ. DDAVP enhances platelet adherence and platelet aggregate growth on human artery subendothelium. Blood. 1984; 64:229-36. [PubMed: 6428488]

Schiffer 2001 . Schiffer CA, Anderson KC, Bennett CL, Bernstein S, Elting LS, Goldsmith M, et al. Platelet transfusion for patients with cancer: Clinical practice guidelines of the American Society of Clinical Oncology. Journal of Clinical Oncology. 2001; 19:1519-38. [PubMed: 11230498]

Schünemann 2011 . Schünemann, HJ.; Oxman, AD.; Higgins, JPT.; Vist, GE.; Glasziou, P.; Guyatt, GH. Chapter 11: Presenting results and 'Summary of findings' tables. In: Higgins, JPT.; Green, S., editors. Cochrane Handbook for Systematic Reviews of Interventions. The Cochrane Collaboration; 2011. Version 5.1.0 (updated March 2011)Available from www.cochranehandbook.org

Shehata 2009 . Shehata N, Tinmouth A, Naglie G, Freedman J, Wilson K. ABO-identical versus non-identical platelet transfusion: a systematic review. Transfusion. 2009; 49:2442-53. [PubMed: 19903296] 
Silliman 2003 . Silliman CC, Boshkov LK, Mehdizadehkashi Z, Elzi DJ, Dickey WO, Podlosky L, et al. Transfusion-related acute lung injury: epidemiology and a prospective analysis of etiologic factors. Blood. 2003; 101(2):454-62. [PubMed: 12393667]

Simpson 2012 . Simpson E, Lin Y, Stanworth S, Birchall J, Doree C, Hyde C. Recombinant factor VIIa for the prevention and treatment of bleeding in patients without haemophilia. Cochrane Database of Systematic Reviews. 2012; (3) DOI: 10.1002/14651858.CD005011.pub4.

Slichter 1980 . Slichter SJ. Controversies in platelet transfusion therapy. Annual Reviews of Medicine. 1980; 31:509-40.

Slichter 2005 . Slichter SJ, Davis K, Enright H, Braine H, Gernsheimer T, Kao KJ, et al. Factors affecting posttransfusion platelet increments, platelet refractoriness, and platelet transfusion intervals in thrombocytopenic patients. Blood. 2005; 105:4106-14. [PubMed: 15692069]

Slichter 2007 . Slichter SJ. Evidence-based platelet transfusion guidelines. Hematology (American Society of Hematology Education Program). 2007:172-8.

Slichter 2010 . Slichter SJ, Kaufman RM, Assmann SF, McCullough J, Triulzi DJ, Strauss RG, et al. Dose of prophylactic platelet transfusions and prevention of haemorrhage. New England Journal of Medicine. 2010; 362:600-13. [PubMed: 20164484]

Solomon 1978 . Solomon J, Bofenkamp T, Fahey JL, Chillar RK, Beutler E. Platelet prophylaxis in acute non-lymphoblastic leukemia. The Lancet. 1978; 1(8058):267.

Solomon 2009 . Solomon C, Pichlmaier U, Schoechl H, Hagl C, Raymondos K, Scheinichen D, et al. Recovery of fibrinogen after administration of fibrinogen concentrate to patients with severe bleeding after cardiopulmonary bypass surgery. British Journal of Anaesthesia. 2010; 104(5): 555-62. [PubMed: 20348140]

Sorensen 2011 . Sørensen B, Tang M, Larsen OH, Laursen PN, Fenger-Eriksen C, Rea CJ. The role of fibrinogen: a new paradigm in the treatment of coagulopathic bleeding. Thrombosis Research. 2011; 128(Suppl 1):S13-16. [PubMed: 22221845]

Stanworth 2010 . Stanworth SJ, Dyer C, Choo L, Bakrania L, Copplestone A, Llewelyn C, et al. Do all patients with hematologic malignancies and severe thrombocytopenia need prophylactic platelet transfusions? Background, rationale, and design of a clinical trial (trial of platelet prophylaxis) to assess the effectiveness of prophylactic platelet transfusions. Transfusion Medicine Reviews. 2010; 24(3):163-71. [PubMed: 20656185]

Stanworth 2013 . Stanworth SJ, Estcourt LJ, Powter G, Kahan B, Dyer C, Choo L, et al. A noprophylaxis platelet transfusion strategy for hematologic cancers. New England Journal of Medicine. 2013; 368(19):1771-80. PUBMED: WOS: 000318540000005. [PubMed: 23656642]

Sterne 2011 . Sterne, JAC.; Egger, M.; Moher, D.; Higgins, JPT.; Green, S., editors. Cochrane Handbook for Systematic Reviews of Intervention. The Cochrane Collaboration; 2011. Chapter 10: Addressing reporting biases. Version 5.1.0 (updated March 2011)Available from www.cochrane-handbook.org

Taylor 2010 . Cohen, H.; Mold, D.; Jones, H.; et al. Serious Hazards of Transfusion (SHOT) Steering Group. The 2009 Annual SHOT Report. Taylor, C., editor. SHOT Steering Group; 2010 .

Tierney 2007 . Tierney JF, Stewart LA, Ghersi D, Burdett S, Sydes MR. Practical methods for incorporating summary time-to-event data into meta-analysis. Trials. 2007; 8(16) DOI: 10.1186/1745-6215-8-16.

Tinmouth 2007 . Tinmouth, AT. Canadian Blood Services. 4th Edition. Canadian Blood Services; 2007. Chapter 18: Platelet transfusion, alloimmunization and management of platelet refractoriness.

TRAP 1997 . The Trial to Reduce Alloimmunization to Platelets Study Group. Leukocyte reduction and ultraviolet B irradiation of platelets to prevent alloimmunization and refractoriness to platelet transfusions. New England Journal of Medicine. 1997; 337:1861-70. [PubMed: 9417523]

Verma 2009 . Verma A, Agarwal P. Platelet utilization in the developing world: strategies to optimize platelet transfusion practices. Transfusion and Apheresis Science. 2009; 41(2):145-9. [PubMed: 19716339]

Wandt 2012 . Wandt H, Schaefer-Eckart K, Wendelin K, Pilz B, Wilhelm M, Thalheimer M, et al. Therapeutic platelet transfusion versus routine prophylactic transfusion in patients with 
haematological malignancies: an open-label, multicentre, randomised study. Lancet. 2012; 380(9850):1309-16. [PubMed: 22877506]

Wardrop 2013 . Wardrop D, Estcourt L, Doree C, Hopewell S, Stanworth S, Murphy MF. Antifibrinolytics (lysine analogues) for the prevention of bleeding in patients with haematological disorders. Cochrane Database of Systematic Reviews. 2013; (7) DOI: 10.1002/14651858.CD009733.pub2.

WHO 1979 . WHO. WHO Handbook for Reporting Results of Cancer Treatment. World Health Organisation; Geneva: 1979. WHO Offset publication No. 48

Zeng 2011 . Zeng Y, Duan X, Xu J, Ni X. TPO receptor agonist for chronic idiopathic thrombocytopenic purpura. Cochrane Database of Systematic Reviews. 2011; (7) DOI: 10.1002/14651858.CD008235.pub2.

\section{References to other published versions of this review}

Estcourt 2012a . Estcourt L, Stanworth SJ, Doree C, Hopewell S, Murphy MF, Tinmouth A, et al. Prophylactic platelet transfusion for prevention of bleeding in patients with haematological disorders after chemotherapy and stem cell transplantation. Cochrane Database of Systematic Reviews. 2012; (5) DOI: 10.1002/14651858.CD004269.pub3.

Stanworth 2004 . Stanworth SJ, Hyde C, Heddle N, Rebulla P, Brunskill S, Murphy MF. Prophylactic platelet transfusion for haemorrhage after chemotherapy and stem cell transplantation. Cochrane Database of Systematic Reviews. 2004; (4) DOI: 10.1002/14651858.CD004269.pub2. 